2016-07-15

\title{
Capital costs in tidal stream energy projects - A spatial approach
}

Vazquez, A

http://hdl.handle.net/10026.1/8706

10.1016/j.energy.2016.03.123

Energy

All content in PEARL is protected by copyright law. Author manuscripts are made available in accordance with publisher policies. Please cite only the published version using the details provided on the item record or document. In the absence of an open licence (e.g. Creative Commons), permissions for further reuse of content should be sought from the publisher or author. 
This is the author's accepted manuscript. The final published version of this work (the version of record) is published by Elsevier in Energy 2016 available at: http://dx.doi.org/10.1016/j.energy.2016.03.123. This work is made available online in accordance with the publisher's policies. Please refer to any applicable terms of use of the publisher.

\title{
Capital costs in tidal stream energy projects - a spatial approach
}

\author{
A. Vazquez ${ }^{1 *}$, G. Iglesias ${ }^{2}$ \\ ${ }^{1}$ University of Santiago de Compostela, EPS, Hydraulic Eng., Campus Univ. s/n, 27002 Lugo, Spain \\ ${ }^{2}$ University of Plymouth, School of Marine Science and Engineering, Drake Circus, Plymouth PL4 8AA, UK
}

\begin{abstract}
Tidal stream energy projects involve high amounts of capital, for which ex-ante economic assessments are crucial. Unfortunately, the existing models to estimate the capital costs of a tidal stream energy project are often oversimplified. Focused on single estimates on a per installed power basis, such models fail to capture the all-important sensitivity of the capital costs to project site-specific characteristics (water depth, distance to the shoreline, etc.) The objective of this work is twofold: (1) to develop a new formulation for estimating the capital costs of a tidal stream farm, and (2) to implement this formula in a Matlab-based tool coupled with a Navier-Stokes solver and thus deliver the spatial distribution of this cost. As a case study, the new tool is applied to the Bristol Channel - the single largest resource area for tidal energy in the UK. Here, the best areas to install tidal stream farms are identified, with a cost comparable to that of offshore wind energy. Simulation results show that the proposed method is more efficient than the existing approaches. The results of this work have relevant policy implications in that they serve as decision criteria for allocating tidal stream projects and for designating supporting mechanisms.
\end{abstract}

Keywords: tidal stream energy; levelised cost of energy; capital costs; economic map; geospatial variability; Bristol Channel

\footnotetext{
${ }^{*}$ Corresponding author; email: angela.vazquez@usc.es; tel.: +34982823295; fax: +34982285926
} 


\section{Introduction}

As a result of public concerns about sustainability and growing legislation aimed at mitigating the effects of global climate change, utilities around the world are looking for new sources of clean power [1-4]. Tidal stream energy, which taps the kinetic energy of tidal currents, is arguably one of the most promising renewables for meeting future energy needs [5-7]. The predictable character of the tidal resource is a great advantage with respect to other renewables such as wind energy [8]- highly weather-dependent and thus, more unreliable [9-11]. Recent studies on tidal stream energy also suggest that this renewable is associated with a significant availability in a number of areas worldwide [1216] and with lower environmental impacts relative to tidal barrages [17-20] - a crucial prerequisite for ensuring public acceptance [21] and positive externalities [22,23]. Notwithstanding, tidal stream energy is not without downsides. Above all else, its cost is arguably the main barrier to market penetration [24-27]. The required scale of capital, together with the uncertainty and unpredictability of the costs and future revenue streams, weighs on potential investments, which are crucial to the development of this emerging sector $[28,29]$.

In this context, the development of cost modelling tools for tidal stream energy, with particular emphasis on estimating capital expenditures (CAPEX), is called to play a decisive role in strengthening the confidence of potential investors [28]. Capital costs are vital elements of the overall and relative economics of electricity technologies [30]. Actually, they represent more than $70 \%$ of the levelised cost of tidal stream energy (LCOE), while the remaining percentage corresponds to operating and maintenance expenditures (OPEX) [31,32]. It is also of importance that the capital investment is incurred before tidal stream installations start operating, which compromises a debt that has to be paid back during the lifetime of the installation, expected at 20 years $[33,34]$. 
Thus, the timescale for achieving a return on these capital investments is long and surrounded by uncertainties over market regulations and prices, which are quite volatile.

Previous works used CAPEX quotations on a per $\mathrm{kW}$ or MW basis to estimate LCOE for tidal stream energy $[30,33-35]$ and to perform cross-technological comparisons $[31,36]$

(Table 1). Using average cost values that are normalised to the installed capacity (Table 1) is an effective approach, especially given the lack of project- or device- specific cost data in the public domain [30]. However, considering the database on which such cost assessments are based - consisting of the technology development at the $\mathrm{kW}$ and MW scale, across different continents (Europe, North America, etc.) [35] - it is clear that new methods are needed to improve the specificity of the assessments, since such costs will depend upon the specific site $[34,34]$. Site considerations include water depth, mean water speed, rated power and rotor diameter of the turbine. The location, and in particular the distance to the shoreline, will also dictate the electrical cable length and the size and design of the foundation [37], as will be discussed later. Above all, water depth and distance to shore are two of the main cost drivers in offshore projects, for they reflect the level of environmental loads to which a tidal stream energy converter is exposed, determinate the rotor size and affect the electricity loses, among others [38]. Hence, these variables have a significant impact on cost figures and must be carefully considered.

The overarching objective of this work is to develop a new formula for estimating the capital costs of a tidal stream energy project, located at a given place. In this new formula, the CAPEX are obtained on the basis of the water depth and the distance to the shoreline, rather than on a per MW basis. Therefore, the relationship between the capital costs and the location is taken into account. In this new formula, the capital investment is balanced with the energy production, in line with the LCOE approach. In this manner, we define the 
levelised capital cost of energy (LCaOE), which incorporates all of the specifics and available data - plant characteristics (diameter, distance from the shoreline, and number of turbines) and energy produced - in a single figure. The LCaOE thus defined constitutes an indicator of the capital investment in relation with the revenues (energy produced) over the entire life of the tidal stream installation, and can therefore serve as a decision criterion parameter. In addition, this formula is implemented in an ad hoc Matlab-based tool coupled with a Navier-Stokes solver which offers a unique spatial distribution of the different input parameters, and the $\mathrm{LCaOE}$ itself, in the form of maps. The Bristol Channel (UK) is used as a case study to illustrate the new method.

Apart from its novelty, the present work has added value for a number of reasons. First, the location chosen for the case study, the Bristol Channel (UK), is the single largest resource area for tidal energy in the UK, and is considered of national strategic significance to meet the future demand for low carbon energy [39]. However, it is a complex hydrodynamic system which supports a wide range of marine habitats, marine communities and economic interests, as well as providing a major sea transport route into the UK heartland [39]. By means of the LCaOE maps, it is possible to identify the optimal locations for tidal stream systems, where they can be considered a more profitable option than other marine renewable technologies. The current tools based on graphs and tables do not allow these zones to be detected. Therefore, the results here presented can help in policy- and decisionmaking. Second, costs are not static measurements, and in this regard our approach allows for flexibility. The integration of the LCaOE formula in a Matlab-based tool allows the user to specify and update the assessment parameters (LCaOE inputs), as data become publicly available. Third, thanks to the alignment of the LCaOE (new parameter defined here as such) with the LCOE, the latter can be easily derived by considering a given percentage of participation of the capital costs in the overall costs. 
This article is structured as follows. Section 2 deals with the presentation and implementation of the new formula to estimate the $\mathrm{LCaOE}$ in a Matlab-based tool designed ad hoc. This implementation is illustrated by means of a case study in the Bristol Channel. Section 3 presents the results and discussion. Finally, conclusions are drawn in Section 4.

\section{Materials and methods}

Capital expenditures (CAPEX) are costs incurred before the plant starts operating. They include all expenses associated with the construction of the elements of the plant, their deployment and connection to the electrical grid, and are typically composed of different cost categories, namely: (1) rotor costs $\left(C_{R}\right),(2)$ cable costs $\left(C_{C}\right),(3)$ costs of foundations $\left(C_{F}\right),(4)$ installation costs $\left(C_{I}\right)$ and (5) grid connection costs $\left(C_{G}\right)[24,30,57]$. Not all the categories have the same level of participation in the overall CAPEX value (Figure 1).

\subsection{LCaOE formulation}

In economic assessments, capital expenditures (CAPEX) are usually included as a LCOE input parameter $[30,33,34,40,41]$ :

$$
L C O E=\frac{P V(C A P E X)+P V(O P E X)}{P V(A E P)} .
$$

In line with the LCOE parameter, a new variable can be defined: the levelised capital cost of energy ( $\mathrm{LCaOE})$, which represents the sum of capital expenditures with respect to the lifetime generated energy (AEP), in terms of present value equivalent:

$$
L C A O E=\frac{P V(C A P E X)}{P V(A E P)} .
$$


Capital expenditures are normally a one-time cost, incurred in the year zero or at the end of the first period considered; whereas the energy is produced during the lifetime of the installation. To make the assessment consistent, the present value of the stream of the capital costs is calculated and converted to an equivalent annual cost using a standard annuity formula $[25,30,42]$ :

$$
L C a O E=\frac{P V(C A P E X)}{P V(A E P)}=\frac{\sum_{t=0}^{t=T}\left(\frac{C A P E X}{(1+r)^{t}}\right)\left(\frac{r}{1-(1+r)^{-T}}\right)}{\left(\sum_{t=1}^{t=T} O_{t}\right) / T}
$$

where $r$ is the interest rate that takes into account both the time value of money and the risk of the investment (aspects that vary by circumstance, location and time period [40]), $O_{t}$ is the electrical output in year $t$, and $T$ is the lifetime of the installation (20 years) $[33,34]$. Nowadays energy projects involve high capital costs and, due to their novelty, are associated with high technological risks. In this respect, current analyses typically consider a discount rate of the order of $10 \%[33,34]$.

From the breakdown of capital costs categories $\left(C_{i}\right)$ and their associated percentages $\lambda_{i}$ (Figure 1), the CAPEX in Eq. (3) can be obtained:

$$
\text { CAPEX }=\left(C_{i} / \lambda_{i}\right)
$$

These categories of costs $\left(C_{i}\right)$ can be estimated by means of functions of site-specific characteristics and tidal farm parameters, as explained below. In particular, the distances to the shoreline and the water depth have the greatest bearing on the CAPEX values. Note that these variables are directly related with the diameter of the turbines and the length of the exporting cable, respectively, in that the diameter is usually calculated as a percentage of the water depth [43] and the exporting cable connects the tidal stream farm with a landbased electrical substation. 
Rotor costs, $C_{R}$, are mainly influenced by the rotor diameter $(D)$. This relationship is not linear. Upscaling turbine blades imposes higher thickness to increase the mass, the stability and resistance of the structure, which is exposed to harsh environments. Punctual estimates were reported for a range of diameters (Bryden, 1998) which were converted in a smooth function (Eq.(5)). Taking into account that a farm is composed by a number of converters $n$, the total rotor cost function can be expressed as:

$$
C_{R}=80.388_{(2010)} n \mathrm{D}^{2.687}
$$

Note that the adjustment coefficient is expressed in cost (GBP) per meter of diameter and this cost is referred to 2010. It is important to take into account the reference year of the costs in order to ensure that all CAPEX categories are being calculated on an equitable basis. Data from earlier years should be converted according to the appropriate year [30].

As regards the cable costs $\left(C_{C}\right)$, they are mainly estimated on the basis of the exporting cable cost, which is the cable that allows delivering the electricity produced to a land-based electrical substation $[44,45]$. They are highly sensitive to the cable length, which is directly related to the distance to shoreline[46]. Previous works have assessed this relationship [43], which can be adjusted to a function for the cable costs as:

$$
C_{C}=169.79_{(2010)} L
$$

where $L$ is the length of the extorting cable in meters. Note that the function to estimate the cable costs refers also to $2010 \mathrm{GBP}$.

The cost of the foundations, $C_{F}$, (construction and installation) represents from $20 \%$ to $25 \%$ of an offshore project cost [47]. The water depth has a strong impact on the foundation type structure and the geology also affects the choice of the foundation [48]. An 
estimation of the cost including the water depth $(d)$ in main input parameter can be done as follows [47]:

$$
\left.\begin{array}{lr}
0<d<30 \mathrm{~m} & C_{F}=0.1875+1.2510^{-5} d^{3} \\
30<d<60 \mathrm{~m} & C_{F}=0.4375+510^{-5} d^{3} \\
d>60 \mathrm{~m} & C_{F}=0.1875+0.02 d
\end{array}\right\}
$$

These costs are given in GBP per MW.

On these grounds, the $\mathrm{LCaOE}$ formula of Eq. (3) can be rewritten:

$$
L C a O E=\frac{\left(\frac{\left(80.388 n D^{2.687}+169.79 L+C_{F} f(d)+\left(\sum_{i=c-3}^{c} C_{i}\right)\right)}{(1+r)^{t}}\right)\left(\frac{r}{1-(1+r)^{-T}}\right)}{\left(\sum_{t=1}^{t=T} O_{t}\right) / T} .
$$

Note that $C_{F}$ is introduced in the formula as a function of the water depth $(d)$.

The above mentioned categories of cost can be used to extend the estimations to the total capital costs, as follows:

$$
C A P E X=\left(\sum C_{i}\right)=\frac{\left(C_{R}+C_{C}+C_{F}\right)}{\lambda_{(R+C+F)}},
$$

where $\lambda_{(C+R+F)}$ is combined percentage of rotor, cable and foundation costs.

This relationship can be incorporated in the $\mathrm{LCaOE}$, which in turn results:

$$
L C a O E=\frac{\left(\frac{\left(80.388 n D^{2.687}+169.79 L+C_{F} f(d)\right)\left(\frac{1}{\lambda_{(R+C+F)}}\right)}{(1+r)^{t}}\right)\left(\frac{r}{1-(1+r)^{-T}}\right)}{\left(\sum_{t=1}^{t=T} O_{t}\right) / T} .
$$


As regards the electrical output $\left(O_{t}\right)$, it is a function of the flow velocity $(v(\mathrm{t}))$, the power efficiency of the system $\left(C_{p}\right)$, water density $(\rho)$, swept area $(A)$ and number of converters $(n)$ :

$$
O_{t}=\frac{1}{2} C_{p} \rho A n \int v^{3}(t) d t
$$

where the area can be expressed in terms of the diameter $D$ as follows:

$$
A=\frac{\pi}{4} D^{2}
$$

Substituting in the general LCaOE formula, Eq. (10) yields:

$$
L C a O E=\frac{\left(\frac{\left(80.388 n D^{2.687}+169.79 L+C_{F} f(d)\right)\left(\frac{1}{\lambda_{(R+C+F)}}\right)}{(1+r)^{t}}\right)\left(\frac{r}{1-(1+r)^{-T}}\right)}{\left(\sum_{t=1}^{t=T}\left(\frac{\pi}{8} C_{p} \rho n D^{2} \int v^{3}(t)\right)\right) / T} .
$$

Note that this expression is based on a number of considerations, in addition to the cost parameters. Site-specific characteristics are included via the tidal stream resource (velocity, $v)$, the water depth $(d)$ and the distance to the shoreline $(L)$. Among the technical specifications, the rotor diameter $(D)$, number of converters $(n)$ and power coefficient $\left(C_{p}\right)$ are considered. When it comes to assessing a tidal stream project, all the previous variables have to be considered together, since they are in close relationship. For example, the number of converters is subject to bathymetric constraints, and so is the rotor diameter [34]. The distance to the shoreline depends on the particular location of the tidal stream site, restricted to energetic tidal sites. To account for these relationships, the previous expression (Eq. (13)) is implemented in a new spatial tool, as explained below. 


\subsection{LCaOE implementation}

The previous formulation was implemented in a Matlab-based tool designed ad hoc, which was conceived to be coupled with a Navier-Stokes solver producing (hydrodynamic) numerical modelling results. Therefore, this tool takes into account the all-important spatial and temporal variability of the tidal resource, offering a specific value of $\mathrm{LCaOE}$ for each grid cell within the domain (Bristol Channel, UK).

The hydrodynamic model is based on finite-difference approximations of the Reynoldsaveraged Navier-Stokes equations. Flow conditions at potential tidal energy sites are usually modelled by two-dimensional (2D) depth-averaged models, which are based on the shallow water equations (e.g. [5]). They provide reliable information about current strengths and the feasibility of the site for tidal energy development. The governing equations of this model are shown below. First, Eq. (14) represents the conservation of mass under the assumption of incompressibility.

$$
\frac{\partial \zeta}{\partial t}+\frac{\partial[(d+\zeta) U]}{\partial x}+\frac{\partial[(d+\zeta) V]}{\partial y}=Q
$$

Second, the conservation of momentum is expressed by means of Eq. (15).

$$
\left\{\begin{array}{c}
\frac{\partial U}{\partial t}+U \frac{\partial U}{\partial x}+V \frac{\partial U}{\partial y}-A=-g \frac{\partial \zeta}{\partial x}-\frac{g}{\rho_{0}} \int_{-d}^{\zeta} \frac{\partial \rho}{\partial x} d z+\frac{\tau_{s x}-\tau_{b x}}{\rho_{0}(d+\zeta)}+v_{h} \nabla^{2} \mathrm{U} \\
\frac{\partial V}{\partial t}+U \frac{\partial V}{\partial x}+V \frac{\partial V}{\partial y}-A U=-g \frac{\partial \zeta}{\partial y}-\frac{g}{\rho_{0}} \int_{-d}^{\zeta} \frac{\partial \rho \prime}{\partial y} d z+\frac{\tau_{s y}-\tau_{b y}}{\rho_{0}(d+\zeta)}+v_{h} \nabla^{2} \mathrm{~V}
\end{array}\right\}
$$

Finally, the transport equation, which is solved for both salinity and temperature is:

$$
\frac{\partial(\zeta+d) c}{\partial t}+\frac{\partial[(d+\zeta) U c]}{\partial x}+\frac{\partial[(d+\zeta) V c]}{\partial y}=D_{h} \nabla^{2} c-\lambda_{\mathrm{d}}(d+\zeta) c+R
$$


These equations involve a number of parameters. The terms $U$ and $V$ stand for the vertically integrated velocity components in the east $(x)$ and north $(y)$ directions, respectively; $d$ is the local water depth relative to a reference plane; $Q$ represents the intensity of mass sources per unit area; $f$ is the Coriolis parameter, $v_{h}$ is the kinematic horizontal eddy viscosity, $\rho_{o}$ is the reference density, $\rho^{\prime}$ is the anomaly density, $\tau_{s x}, \tau_{s y}, \tau_{b x}$ and $\tau_{b y}$ are the shear stress components. As regards the transport equation, $c$ stands for salinity or temperature, $D_{h}$ is the horizontal eddy diffusivity, $\lambda_{d}$ represents the first order decay process, and $R$ is the source term per unit area [5].

The hydrodynamic model in the present study used a staggered grid (the Arakawa-C grid). In the cells of this grid, the water levels $\zeta$ are computed at the centres, whereas the flow velocity components ( $U$ and $V$ ) are defined at the mid-points of the grid cell faces to which they are perpendicular. The horizontal advection terms in Eqs. (1)-(3) are discretized by means of the Cyclic method [49]. For its part, the temporal discretization the model resorts to a semi-implicit ADI algorithm with two time levels per iteration.

The computational domain consisted of $500 \mathrm{~m} \times 500 \mathrm{~m}$ cells, and the bathymetry for the model was interpolated from GEBCO data. Along the open boundary (at Celtic Sea), a Dirichlet boundary condition was imposed with the sea level prescribed as a function of time using nine tidal harmonics (M2, S2, N2, K2, K1, O1, P1, Q1, M4). These tidal harmonics were obtained from the global ocean tide model TPXO 7.2 [50], which has been shown to produce good results in previous works $[5,17,18,33,51,52]$. Salinity and temperature at the open boundary were imposed using data from the British Oceanographic Data Centre [53]. At the land margins the boundary conditions were free slip (i.e. zero shear stress) and null flow. The shear stress at the sea-bed was computed from:

$$
\tau_{b x}=\frac{1}{C_{2 D}^{2}} \rho_{0} g U \sqrt{\left(U^{2}+V^{2}\right)}, \quad \tau_{b y}=\frac{1}{C_{2 D}^{2}} \rho_{0} g V \sqrt{\left(U^{2}+V^{2}\right)}
$$


where $\mathrm{C}_{2 \mathrm{D}}$ is the $2 \mathrm{D}$ Chézy coefficient, which depends on the water depth and bottom roughness. This dependency can be written, in terms of the Manning coefficient, $n$, as:

$$
C_{2 D}=\frac{\sqrt[6]{(d+\zeta)}}{n}
$$

The value of the Manning coefficient was determined as a function of the water depth following Dias and Lopes [54].

The model was run for 50 days, being the first 31 days the spin-up period, which aims to adjust dynamically the flow field so that the initial conditions do not affect the numerical results during the period of interest (a spring neap cycle from 14 March 2011 to 28 March 2011) [33]. The initial hydrodynamic conditions were null velocity and surface elevation throughout the grid (cold-start) [55]. The model was validated against measured tide levels at four gauge stations obtained from the UK tide gauge network [53] and tidal stream data given at five tidal diamonds taken from the Admiralty Chart No. 1165. A high level of correlation between observed and predicted data was obtained $\left(\mathrm{R}^{2}>0.87\right)$ [34].

Upon validation, the numerical model results were coupled with the Matlab-based tool. This tool resolves the spatial distribution of the $\mathrm{LCaOE}$, on the basis of the following inputs:

- Diameter $(D)$. The rotor diameter is constrained by the water depth. In this regard, the tool imports the lowest astronomical tide levels (LAT) at each grid cell from the numerical model, and calculates the maximum diameter as the $70 \%$ of the LAT [43]. Since the diameter is normally expressed in steps of 0.5 , the tool rounds the diameter to the nearest 0.5 point. 
- Total number of turbines $(n)$. This is based on the maximum number of turbines that a grid cell can accommodate and so it also subject to spatial constraints. Device interactions can cause reductions in the available tidal stream energy at a downstream rotor, as demonstrated $[18,33]$. Therefore, it is recommended to leave a lateral spacing of at least 5 diameters and a longitudinal spacing of 10 diameters to avoid negative effects [56]. On these grounds, the tool estimates the size of the farm on the basis of the diameter (Figure 2).

- Cable length $(L)$. The energy output is normally exported to a land-based electrical infrastructure, which corresponds, preferably, to the nearest shoreline point to the farm . In this case, the length of the exporting cable is calculated on the basis of the nearest land point for each grid cell.

- Electrical ouptut $\left(O_{t}\right)$ : it is estimated for each grid cell by means of the numerical integration of a time series of velocity covering a spring-neap cycle (see Eq. (11)). This velocity is estimated through the hydrodynamic numerical model.

\section{Results and discussion}

\subsection{Spatial distribution of capital costs: LCaOE map}

The LCaOE tool was applied with the input data shown in Table 2. The combined percentage of the rotor, cable and foundations costs $\left(\lambda_{(R+C+F)}\right)$ was stablished on the basis of the breakdown of capital costs found in a number of sources [24,31,57]. The power coefficient $\left(C_{p}\right)$ represents the percentage of power that can be extracted from the fluid stream taking into account losses and Betz's law [58], and for marine turbines has typically a value in the range $0.30-0.50$ [59]. Additionally, a discount rate of $10 \%$ was used [60]. The lifetime of the installation was set to 20 years, which is the expected time that a tidal 
stream energy installation will be working prior to the occurrence of gradual degradation due to the environmental conditions [33]. As a result, the LCaOE map was obtained, in which the maximum values of $\mathrm{LCaOE}$ in the color scale were set to $£ 1 \mathrm{~kW} \mathrm{~h}{ }^{-1}$ for better visualization (Figure 3). According to the $\mathrm{LCaOE}$ values, the study domain was classified into three areas (I, II and II) (Table 3):

- Area I encompasses an extension of 1/3 of the total assessed space. Here, LCaOE values are below $£ 0.21$ per $\mathrm{kW}$ h. This is considered a "strike price", i.e. the maximum $\mathrm{LCaOE}$ to provide adequate returns for investors over a 20-year period (lifetime of tidal stream farms) and to maintain momentum in the tidal stream energy sector [37]. On this basis, Area I represents the "viable" area for tidal stream energy projects. Indeed, the most frequent LCaOE values herein obtained are between $£ 0 \mathrm{~kW} \mathrm{~h}^{-1}$ and $£ 0.050 \mathrm{~kW} \mathrm{~h}^{-1}$ (Figure 4), which are comparable to onshore wind energy capital costs (Figure 5). Note that wind energy is considered, among the marine renewable energies, the most mature and costeffective nowadays [31]. The highest LCaOE range in this area would deliver LCOE values in accordance with the central capital cost estimate for tidal stream energy (Figure 5). As regards the LCaOE input parameters, Area I is characterized by mean spring tide velocities in the range 1-2 $\mathrm{m} \mathrm{s}^{-1}$, and up to $3 \mathrm{~m} \mathrm{~s}^{-1}$ in some areas (Figure 4). These values are typical of areas for first generation devices [61]. Rotor diameters in Area I have values mostly between 10-25 m (Figure 4), which correspond to shallow water depths (Figure 6). This is in line with previous predictions to the effect that tidal team farms in deep waters would be very costly if compared with shallow waters, since the structure, foundation and moorings impose higher structural requirements [62]. Besides, the resource located in water depths of 10-30 $\mathrm{m}$ is generally more accessible for energy extraction than deeper offshore tidal sites (where it may be technically difficult to harness a large fraction of the available energy). In shallow areas, a turbine can be designed to occupy a greater 
proportion of the vertical water column. Moreover, shallow waters are commonly closer to the shoreline. The distance to shore is a significant parameter in offshore installations, and short distances may be desirable, since both cable costs and transmission losses are reduced. Indeed, Area I has cable lengths (shoreline distances) below $20 \mathrm{~km}$ (Figure 7). In particular, the most frequent cable lengths are 5 and $10 \mathrm{~km}$ (Figure 4), in the range of the offshore distance of the greater part of offshore wind energy projects in the UK ([63].

- Area II delimitates a zone with LCaOE values between $£ 0.21 \mathrm{~kW} \mathrm{~h}^{-1}$ and $£ 0.42 \mathrm{~kW} \mathrm{~h}^{-1}$ (Figure 3). The upper boundary $\left(£ 0.42 \mathrm{~kW} \mathrm{~h}^{-1}\right)$ corresponds to the highest value estimated in the literature for tidal stream energy (Figure 5), and therefore this area covers tidal sites in which the exploitation may not be competitive now, and may depend on future cost reductions brought about by economies of scale, learning rates, etc. $\mathrm{LCaOE}$ values in this area have a distribution in which all the values between $£ 0.21 \mathrm{~kW} \mathrm{~h}^{-1}$ and $£ 0.42 \mathrm{~kW} \mathrm{~h}^{-1}$ have more or less the same frequency (Figure 4). Area II is characterized by lower mean spring tide velocities than Area I (Figure 4), approximately $1 \mathrm{~m} \mathrm{~s}^{-1}$, with maximum values near $1.5 \mathrm{~m} \mathrm{~s}^{-1}$. These values are typical of areas for second generation devices [61]. Area II is still in the shallow water region (Figure 6), which may compensate for the lower velocities experienced here in that lower structural requirements (less costly) would be imposed. The rotor diameters in this area are mainly in the range of 20-25 m (Figure 4), in line with commercial designs such as the SeaGen turbine from marine current turbines [64] Cable lengths are greater than in Area I, typically between $5 \mathrm{~km}$ and $20 \mathrm{~km}$ (Figure 4). Greater distances to shoreline impose a challenge the maintenance operations, since the weather windows are reduced with the increase of the offshore distance [3].

- Area III includes the remaining space, characterized by LCaOE values above $£ 0.42 \mathrm{~kW}$ $\mathrm{h}^{-1}$ (Figure 3), with LCaOE values predominantly above $£ 1 \mathrm{~kW} \mathrm{~h}^{-1}$ (Figure 4). This 
constitutes a high value, especially considering that operational expenditures must be added to obtain total LCOE values. Indeed, velocities within this area are below $1 \mathrm{~m} \mathrm{~s}^{-1}$, which in principle would not be attractive for tidal stream energy harnessing [61] (Figure 4). Therefore, Area III delimitates spaces that would be left for other purposes, as discussed in Section 3.3. Besides, water depths in Area III correspond to deep water (rotor sizes in the range of 30-40 m) (Figure 4), and constructing in deep offshore sites far from the shoreline is very challenging due to short weather windows and large travelling distances (indeed, in this area cable lengths reach no less than $35 \mathrm{~km}$ (Figure 7)).

\subsection{Traditional vs. new approach}

To demonstrate the application of the new approach, we obtained the LCaOE on the basis of CAPEX quotations per installed power unit, by using the following expression (see Appendix for further details)

$$
L C a O E=(C A P E X) \frac{P V\left(V r^{3}\right)}{P V\left(\int_{1}^{T} v^{3}\right)}
$$

To this aim, a CAPEX value of $£ 4.30 \mathrm{~m} / \mathrm{MW}$ (Table 1) was used. The installed power per grid cell was based on the rated velocity $\left(V_{r}\right)$, calculated as the mean spring velocity at the given grid cell. Results show significant differences between the estimates obtained with the new and conventional approaches (Figure 3 and 8, respectively), both in terms of $\mathrm{LCaOE}$ values and spatial distribution.

The new approach distributes the cost according to diameter size, available resource and length from the shoreline; whereas the conventional approach distributes the cost mainly on the basis of the velocity ratio $\left(P V\left(V r^{3}\right) / P V\left(\int_{1}^{T} v^{3}\right)\right)$, see Eq.(19)). Thus, for areas with similar ratios, the $\mathrm{LCaOE}$ will be similar, irrespective of whether these areas are far from the shore or impose higher restrictions from an economic point of view. In other words, no 
explicit sensitivity to rotor diameters and cable lengths is captured with the traditional approach. Indeed, in the nearshore areas, where diameter and cable length are small and the tidal resource is more abundant (Figure 8, selected areas) the conventional method overestimates the price, since such areas present the highest values (around $£ 0.18 \mathrm{~kW} \mathrm{~h}^{-1}$ ), which contradicts the expected price results. With the new method, for example, the prices of Area I are more convenient (from $£ 0.01 \mathrm{~kW} \mathrm{~h}^{-1}$ to $£ 0.10 \mathrm{~kW} \mathrm{~h}^{-1}$ most of them (Figure 4)). In areas far from the shore, where diameters can be longer and the resource is not so abundant, the conventional approach underestimates the cost. Whereas in our approach the values in low resource areas, far from the shoreline and allowing for large diameters are above $£ 1 \mathrm{~kW} \mathrm{~h}^{-1}$, the conventional approach estimate maximum values of around $£ 0.25$ $\mathrm{kW} \mathrm{h} \mathrm{h}^{-1}$.

Points $a$ and $b$ (Figure 8 ) have similar velocity rates, with only a difference of $1 \%$. Thus the traditional approach predicts similar cost values of $£ 0.1431 \mathrm{~kW} \mathrm{~h}^{-1}$ and $£ 0.1414 \mathrm{~kW} \mathrm{~h}^{-}$ ${ }^{1}$, respectively. However, based on their characteristics (water depth and distance to shoreline) they are not likely to have the same cost value [38], as predicted by the new approach: $£ 1 \mathrm{~kW} \mathrm{~h}^{-1}$ and $£ 0.1419 \mathrm{~kW} \mathrm{~h}^{-1}$, for point $a$ and $b$, respectively (Table 4 ). Note that for point $b$ both methods yield nearly the same value. In conclusion it can be said that the conventional approach fails to capture the important influence of distance from the shoreline. On the other hand, it estimates higher values for the areas where the resource is good, the diameters small and distance to the shoreline low, which are good areas for tidal stream harnessing.

The previous insights are relevant in that following the conventional approach would lead to biased information for policy makers, and thus investments for tidal stream energy in the 
wrong (not economic) areas could occur - when such areas could be used for other purposes, as discussed in the following section.

\subsection{Policy implications}

The present study has implications for policy- and decision-making at different levels. At a regional level, the results can contribute to designating a balanced technology approach to harnessing the energy production opportunities in the Bristol Channel [39]. This location has a massive marine renewable energy potential (Figure 9), and thus new concepts such as tidal lagoons and tidal fences, deployed in conjunction with tidal stream technology, wave and wind power would provide a good balance between the urgent need to generate low cost energy and to protect the environment [39]. Developing an energy strategy for the Bristol Channel requires a number of factors to be considered, including the cost of energy. Tidal stream energy planners must therefore find ways to harness this energy at an acceptable cost. So far, pre-allocation of future renewable projects has been done on a resource basis (Figure 9). The results presented in this work agree well with previous studies in that the areas pre-selected for tidal stream energy projects coincide with the areas associated with lower LCaOE (see Figure 3 and Figure 9). In addition, our study provides a spatial distribution of costs which can serve as a decision criterion towards a narrower delimitation of the optimum areas to install tidal stream energy farms. It can serve as well to resolve conflicts of use, when two options seem to be feasible (areas with high potential on both tidal range and tidal stream energy), by applying a comparative analysis for example. Thus our contribution addresses both the role of spatial information in coastal research, and its potential to bridge the gap between research and coastal zone management [7]. 
At a higher level, capital costs are also a source of significant concern for governments all over the world. It is important for policy makers and those ocean energy investors to have a picture of the current costs for ocean energy generation and how these are likely to reduce over time [57]. As shown in the previous sections, capital costs are major a component of the total costs and, therefore, require financial support, which can be provided through several instruments, including feed-in tariffs [65]. Feed-in tariffs are subsidies per $\mathrm{kW} h$ generated paid in the form of guaranteed premium prices, combined with a purchase obligation by the utilities. Therefore, they are costs related to energy production, which is in line with the approach presented in this work. Thus, governmental bodies involved in the design or selection of the support mechanisms for building momentum in the tidal stream energy sector may benefit from the results of the present paper.

\section{Conclusions}

A correct decision-making regarding tidal stream energy exploitation should be based on the accurate knowledge of the different factors affecting its exploitation. Amongst them, the capital costs (CAPEX) are paramount. In this work, a new formulation for estimating the levelised capital costs of tidal stream energy $(\mathrm{LCaOE})$ farms is proposed. This approach, unlike the conventional method, accounts for the most relevant site-specific characteristics of a tidal stream energy project, namely the tidal stream resource, water depth (rotor size) or distance to the shoreline (cable length), and shows that tidal energy assessments that consider costs solely on the basis of installed power may represent both an order-of-magnitude overestimation of the resource and a significant oversimplification of CAPEX estimates. To account for the spatio-temporal character of these variables, the 
formulation is implemented in a Matlab-based tool, which is coupled with a Navier-Stokes solver. The Bristol Channel is used to illustrate the capabilities of the new tool.

As a result, a unique spatial distribution of the capital cost within the study domain was obtained, in the form of an LCaOE map. Three areas were identified within this study domain, in order of higher $\mathrm{LCaOE}$ values. Area I encompasses a number of promising sites, with costs comparable to the offshore wind energy sector. Area II includes potentially viable locations. Locations within area III may be used for other purposes, since both the tidal stream resource and the costs are not particularly attractive.

Simulation results showed the proposed method to be more accurate than the existing approach. The results here presented are relevant for policy makers, for they serve to manage the resources in the study area and they provide insight about the level of subsidisation required to maintain momentum in the tidal stream energy sector.

\section{Acknowledgements}

This work was carried out within the framework of the project "Atlantic Power Cluster", funded by the European Commission through its Atlantic Area Programme. The authors wish to thank the British Oceanographic Data Centre for providing tide gauge records. During this work A. Vazquez has been supported by the FPU grant 13/03822 of the Spanish Ministry of Education, Culture and Sport and by the Barrie Foundation through a grant to undertake a predoctoral fellowship at Plymouth University, UK. 


\section{Appendix}

The $\mathrm{LCaOE}$ formula in terms of installed power $\left(n P_{r}\right)$ is defined as follows:

$$
L C a O E=\frac{P V\left(C A P E X P_{r} n\right)}{P V(A E P)},
$$

where CAPEX is a cost quotation on a per $\mathrm{kW}$ or MW basis, AEP is the annual energy production and $P_{r}$ is the rated power, which is function of the rated velocity $v_{r}$ :

$$
P_{r}=\frac{1}{2} C_{p} \rho \frac{\pi}{4} D^{2} v_{r}^{3}
$$

The annual energy production corresponds to the electrical output generated in one year, $O_{t}$ :

$$
O_{t}=\frac{1}{2} C_{p} \rho \frac{\pi}{4} D^{2} n \int v^{3}(t)
$$

Simplifying, the LCaOE formula on the basis of the traditional approach can be expressed as follows:

$$
L C a O E=(C A P E X) \frac{P V\left(v_{r}^{3}\right)}{P V\left(\int v^{3}(t)\right)}
$$




\section{References}

[1] Vicinanza D, Contestabile P, Ferrante V. Wave energy potential in the north-west of Sardinia (Italy). Renewable Energy 2013;50:506-21.

[2] Azzellino A, Ferrante V, Kofoed JP, Lanfredi C, Vicinanza D. Optimal siting of offshore wind-power combined with wave energy through a marine spatial planning approach. International Journal of Marine Energy 2013;3-4:e11-25.

[3] Astariz S, Perez-Collazo C, Abanades J, Iglesias G. Co-located wind-wave farm synergies (Operation \& Maintenance): A case study. Energy Conversion and Management 2015;91:6375.

[4] Veigas M, Ramos V, Iglesias G. A wave farm for an island: Detailed effects on the nearshore wave climate. Energy 2014;69:801-12.

[5] Carballo R, Iglesias G, Castro A. Numerical model evaluation of tidal stream energy resources in the Ría de Muros (NW Spain). Renewable Energy 2009;34:1517-24.

[6] Vazquez A, Astariz S, Iglesias, G. A strategic policy framework for promoting the marine energy sector. 3rd IAHR Europe Congress 2014, Porto - Portugal. ISBN 978- 989-96479-2-3.

[7] Atwater JF, Lawrence GA. Regulatory, design and methodological impacts in determining tidal-in-stream power resource potential. Energy Policy 2011;39:1694-8.

[8] Iglesias G, Sánchez M, Carballo R, Fernández H. The TSE index - A new tool for selecting tidal stream sites in depth-limited regions. Renewable Energy 2012;48:350-7.

[9] Veigas M, Carballo R, Iglesias G. Wave and offshore wind energy on an island. Energy for Sustainable Development 2014;22:57-65.

[10] Veigas M, Iglesias G. Potentials of a hybrid offshore farm for the island of Fuerteventura. Energy Conversion and Management 2014;86:300-8.

[11] Astariz S, Perez-Collazo C, Abanades J, Iglesias G. Towards the optimal design of a colocated wind-wave farm. Energy 2015;84:15-24.

[12] Sanchez M, Carballo R, Ramos V, Iglesias G. Energy production from tidal currents in an estuary: A comparative study of floating and bottom-fixed turbines. Energy 2014;77:80211.

[13] Robins PE, Neill SP, Lewis MJ, Ward SL. Characterising the spatial and temporal variability of the tidal-stream energy resource over the northwest European shelf seas. Appl Energy 2015; 147:510-22.

[14] Neill SP, Hashemi MR, Lewis MJ. The role of tidal asymmetry in characterizing the tidal energy resource of Orkney. Renewable Energy 2014;68:337-50. 
[15] Evans P, Mason-Jones A, Wilson C, Wooldridge C, O'Doherty T, O'Doherty D. Constraints on extractable power from energetic tidal straits. Renewable Energy 2015;81:70722.

[16] Willis M, Masters I, Thomas S, Gallie R, Loman J, Cook A et al. Tidal turbine deployment in the Bristol Channel: a case study. Proceedings of the ICE-Energy 2010;163:93105.

[17] Ramos V, Carballo R, Sanchez M, Veigas M, Iglesias G. Tidal stream energy impacts on estuarine circulation. Energy Conversion and Management 2014;80:137-49.

[18] Ramos V, Carballo R, Álvarez M, Sánchez M, Iglesias G. Assessment of the impacts of tidal stream energy through high-resolution numerical modeling. Energy 2013;61:541-54.

[19] Sanchez M, Carballo R, Ramos V, Iglesias G. Floating vs. bottom-fixed turbines for tidal stream energy: A comparative impact assessment. Energy 2014;72:691-701.

[20] Lee J, Yoo S. Measuring the environmental costs of tidal power plant construction: A choice experiment study. Energy Policy 2009;37:5069-74.

[21] Devine-Wright P. Place attachment and public acceptance of renewable energy: A tidal energy case study. J Environ Psychol 2011;31:336-43.

[22] Vazquez A, Iglesias G. Public perceptions and externalities in tidal stream energy: A valuation for policy making. Ocean Coast Manage 2015;105:15-24.

[23] Vazquez A, Iglesias G. Should tidal stream energy be publicly funded? Evidence from a choice experiment study. 11th European Wave and Tidal Energy Conference (EWTEC) 2015, Nantes France.

[24] Carbon Trust. Accelerating Marine Energy. The potential for cost reduction - insights from the Carbon Trust Marine Energy Accelerator. Carbon Trust 2011;CTC797.

[25] Allan G, Gilmartin M, McGregor P, Swales K. Levelised costs of Wave and Tidal energy in the UK: Cost competitiveness and the importance of "banded" Renewables Obligation Certificates. Energy Policy 2011;39:23-39.

[26] Denny E. The economics of tidal energy. Energy Policy 2009;37:1914-24.

[27] Astariz S, Vazquez A, Iglesias G. Evaluation of the levelised costs of tidal, wave and offshore wind energy. Journal of Renewable and Sustainable Energy 2015;SI 17 in Press.

[28] Leete S, Xu J, Wheeler D. Investment barriers and incentives for marine renewable energy in the UK: An analysis of investor preferences. Energy Policy 2013;60:866-75.

[29] Verbruggen A, Fischedick M, Moomaw W, Weir T, Nadaï A, Nilsson LJ et al. Renewable energy costs, potentials, barriers: Conceptual issues. Energy Policy 2010;38:85061. 
[30] Dalton G, Allan G, Beaumont N, Georgakaki A, Hacking N, Hooper T et al. Economic and socio-economic assessment methods for ocean renewable energy: Public and private perspectives. Renewable and Sustainable Energy Reviews 2015;45:850-78.

[31] Astariz S, Vazquez A, Iglesias G. Evaluation of the levelised costs of tidal, wave and offshore wind energy. 3rd IAHR Europe Congress 2014, Porto - Portugal. ISBN 978- 98996479-2-3.

[32] Carbon Trust. Future Marine Energy: Results of the Marine EnergyChallenge: Cost competitiveness and growth of wave and tidal stream energy.

. Carbon Trust, January 2006. 2006.

[33] Vazquez A, Iglesias G. Device interactions in reducing the cost of tidal stream energy. Energy Conversion and Management 2015;97:428-38.

[34] Vazquez A, Iglesias G. LCOE (levelised cost of energy) mapping: A new geospatial tool for tidal stream energy. Energy 2015;91:192-201.

[35] Ocean Energy Systems (OES). International LCOE for Ocean Energy Technologies. Report 2015; Online: http://www.juliafchozas.com/projects/iea-oes-cost-energy-assessment/.

[36] Johnstone CM, Pratt D, Clarke JA, Grant AD. A techno-economic analysis of tidal energy technology. Renewable Energy 2013;49:101-6.

[37] Renewable UK. Wave and Tidal Energy in the UK. Conquering Challenges, Generating Growth. Issue 2 2013; Online: file:///C:/Users/\%C3\%81ngela/Downloads/ruk13-008-8__wave_and_tidal_soi.pdf.

[38] Ederer N. Evaluating capital and operating cost efficiency of offshore wind farms: A DEA approach. Renewable and Sustainable Energy Reviews 2015;42:1034-46.

[39] Regen SW. Bristol Channel Energy - A balanced technology approach. Discussion Document 2012. Online:

http://regensw.s3.amazonaws.com/bristol_channel_energy_balanced_technology_approach_2 0121127_c541010d0b3719f8.pdf.

[40] Branker K, Pathak MJM, Pearce JM. A review of solar photovoltaic levelized cost of electricity. Renewable and Sustainable Energy Reviews 2011;15:4470-82.

[41] Ouyang X, Lin B. Levelized cost of electricity (LCOE) of renewable energies and required subsidies in China. Energy Policy 2014;70:64-73.

[42] Gross R, Blyth W, Heptonstall P. Risks, revenues and investment in electricity generation: Why policy needs to look beyond costs. Energy Econ 2010;32:796-804.

[43] Bryden IG, Naik S, Fraenkel P, Bullen CR. Matching tidal current plants to local flow conditions. Energy 1998;23:699-709.

[44] Astariz S, Iglesias G. The economics of wave energy: A review. Renewable and Sustainable Energy Reviews 2015;45:397-408. 
[45] Astariz S, Perez-Collazo C, Abanades J, Iglesias G. Co-located wind-wave farms: economic assessment as a function of layout. Renewable Energy 2015;83:837-849.

[46] Astariz S, Abanades J, Perez-Collazo C, Iglesias G. Improving wind farm accessibility for operation \& maintenance through a co-located wave farm: Influence of layout and wave climate. Energy Conversion and Management 2015;95:229-41.

[47] Serrano Gonzalez J., Burgos Payan, M., riquelme Santos, J.,. An improved evolutive algorithm for large offshore wind farm optimum turbines layout. PowerTech, 2011 IEEE Trondheim 2011;pp 1-6.

[48] Pérez-Collazo C, Greaves D, Iglesias G. A review of combined wave and offshore wind energy. Renewable and Sustainable Energy Reviews 2015;42:141-53.

[49] Stelling JLG. Approximation of convective processes by cyclic ADI, methods . 1992.

[50] Dushaw BD, Egbert GD, Worcester PF, Cornuelle BD, Howe BM, Metzger K. A TOPEX/POSEIDON global tidal model (TPXO.2) and barotropic tidal currents determined from long-range acoustic transmissions. Prog Oceanogr 1997;40:337-67.

[51] Ramos V, Carballo R, Álvarez M, Sánchez M, Iglesias G. A port towards energy selfsufficiency using tidal stream power. Energy 2014;71:432-44.

[52] Ramos V, Iglesias G. Performance assessment of Tidal Stream Turbines: A parametric approach. Energy Conversion and Management 2013;69:49-57.

[53] BODC. Brisitsh Oceanographic Data Centre. Online: http://www.bodc.ac.uk/

[54] Dias JM, Lopes JF. Implementation and assessment of hydrodynamic, salt and heat transport models: The case of Ria de Aveiro Lagoon (Portugal). Environmental Modelling \& Software 2006;21:1-15.

[55] Carballo R, Iglesias G, Castro A. Residual circulation in the Ría de Muros (NW Spain): A 3D numerical model study. J Mar Syst 2009;75:116-30.

[56] Malki R, Masters I, Williams AJ, Nick Croft T. Planning tidal stream turbine array layouts using a coupled blade element momentum - computational fluid dynamics model. Renewable Energy 2014;63:46-54.

[57] SI OCEAN. Ocean Energy: Cost of Energy and Cost Reduction Opportunities . Strategic Initiative for Ocean Energy (SI OCEAN) May 2013. Online: http://siocean.eu/en/upload/docs/WP3/CoE\%20report\%203_2\%20final.pdf.

[58] Blunden L, Bahaj A. Tidal energy resource assessment for tidal stream generators. Proc Inst Mech Eng A: J Power Energy 2007;221:137-46.

[59] Yun Seng L, Siong Lee, K. Marine Tidal Current Electric Power Generation: State of Art and Current Status, Renewable Energy, T J Hammons (Ed.), ISBN: 978-953-7619-52-7, InTech, Available from: http://www.intechopen.com/books/renewable-energy/marine-tidalcurrent-electric-power-generation-state-ofart-and-current-status. 
[60] Darling SB, You F, Veselka T, Velosa A. Assumptions and the levelized cost of energy for photovoltaics. Energy Environ.Sci. 2011;4:3133-9.

[61] Lewis M, Neill SP, Robins PE, Hashemi MR. Resource assessment for future generations of tidal-stream energy arrays. Energy 2015;83:403-15.

[62] Ernst \& Young. Cost of a financial support for wave, tidal stream and tidal range generation in the UK. A report for the Departament of Energy and Climate Change and the Scottish Government 2010.

[63] Higgins P, Foley A. The evolution of offshore wind power in the United Kingdom. Renewable and Sustainable Energy Reviews 2014;37:599-612.

[64] Marine Current Turbines Ltd. SeaGen Tidal Energy System Reaches Full Power 1.2MW 2008. Online:

http://www.marineturbines.com/3/news/article/17/seagen_tidal_energy_system_reaches_full_ power__1_2mw/

[65] del Río P, Cerdá E. The policy implications of the different interpretations of the costeffectiveness of renewable electricity support. Energy Policy 2014;64:364-72.

[66] RC, 2015. JRC Ocean Energy Status Report. Joint Research Centre Institute for Energy and 33Transport. 


\section{Figure captions}

Figure 1. Breakdown of capital costs (own elaboration on the basis of Allan et al. [25], Carbon Trust [24] and SI Ocean [57]).

Figure 2. Tidal stream farm layout and spatial constraints.

Figure 3. LCaOE map [values below $£ 0.21 \mathrm{~kW} \mathrm{~h}^{-1}$ correspond to Area I; values between $£ 0.21 \mathrm{~kW} \mathrm{~h}^{-1}$ and $£ 0.42 \mathrm{~kW} \mathrm{~h}^{-1}$ correspond to Area II; and values above $£ 0.42 \mathrm{~kW} \mathrm{~h}^{-1}$ delimitate Area III].

Figure 4. Histograms of LCaOE, diameter, cable length (distance to shoreline), and mean spring velocity for areas I, II and III (defined in Table 3).

Figure 5. LCaOE for other technologies (own elaboration on the basis of Mills (2015)).

Figure 6. Shallow and deep water areas within the Bristol Channel (UK) (“Diameter" values represents the $70 \%$ of LAT, Lowest Astronomical Tide).

Figure 7. Cable length (distance to shoreline).

Figure 8. LCaOE map on the basis of the conventional approach.

Figure 9. Main potential resource areas for wind, wave and tidal energy (own elaboration on the basis of Regen SW ([39]). 


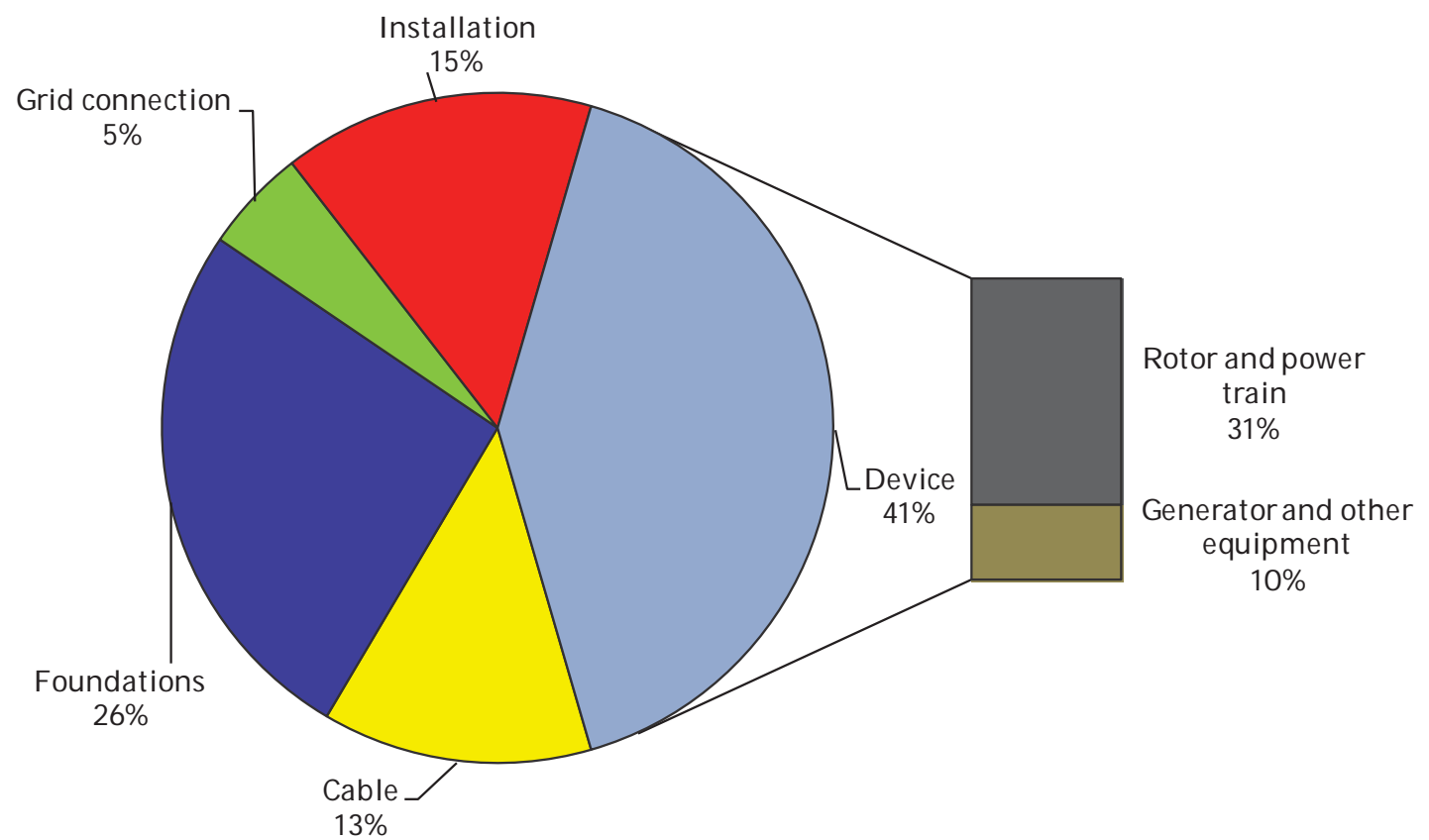




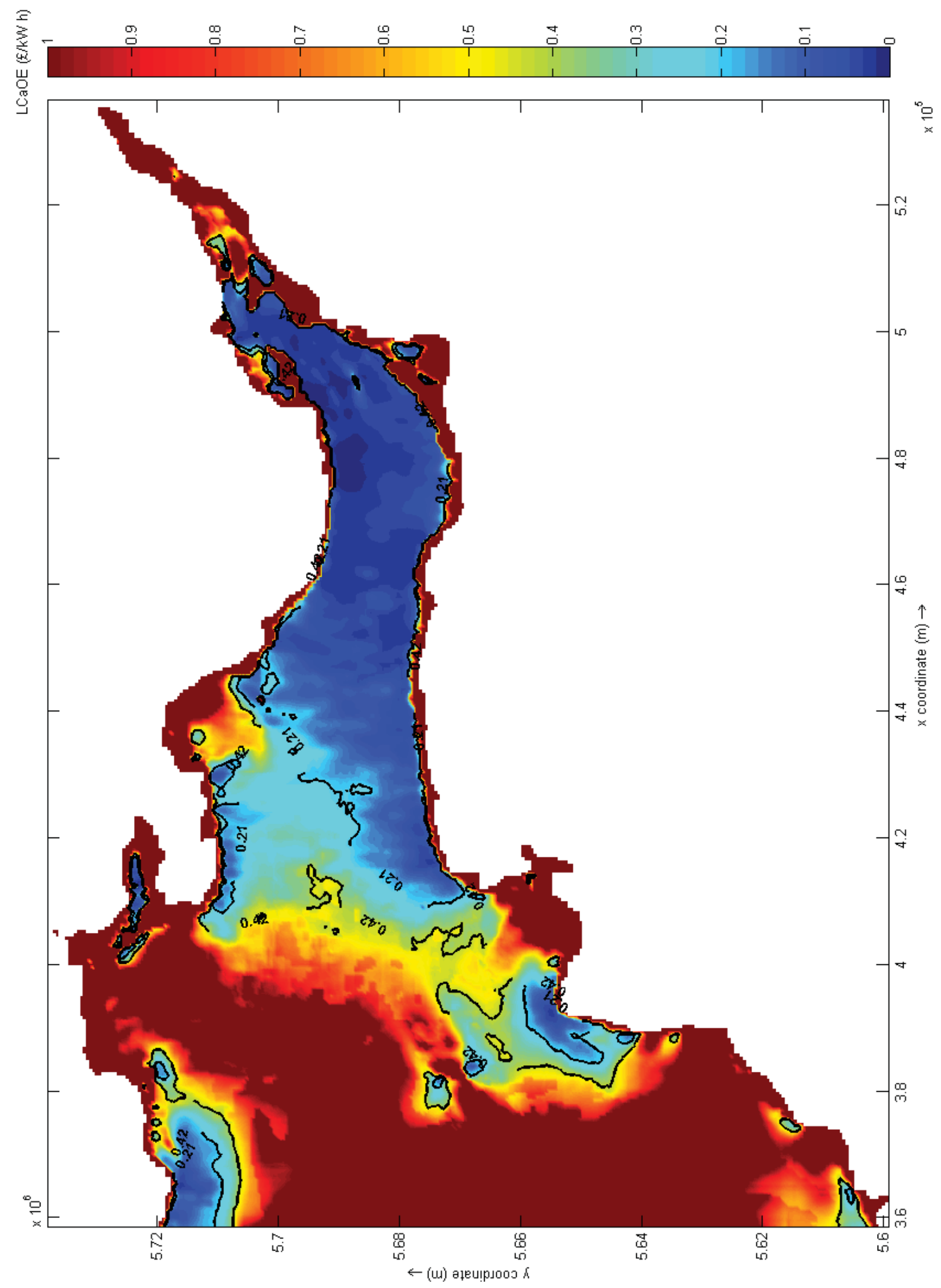

$m$
$\stackrel{0}{\frac{0}{5}}$
$\frac{0}{2}$
$\frac{0}{4}$ 

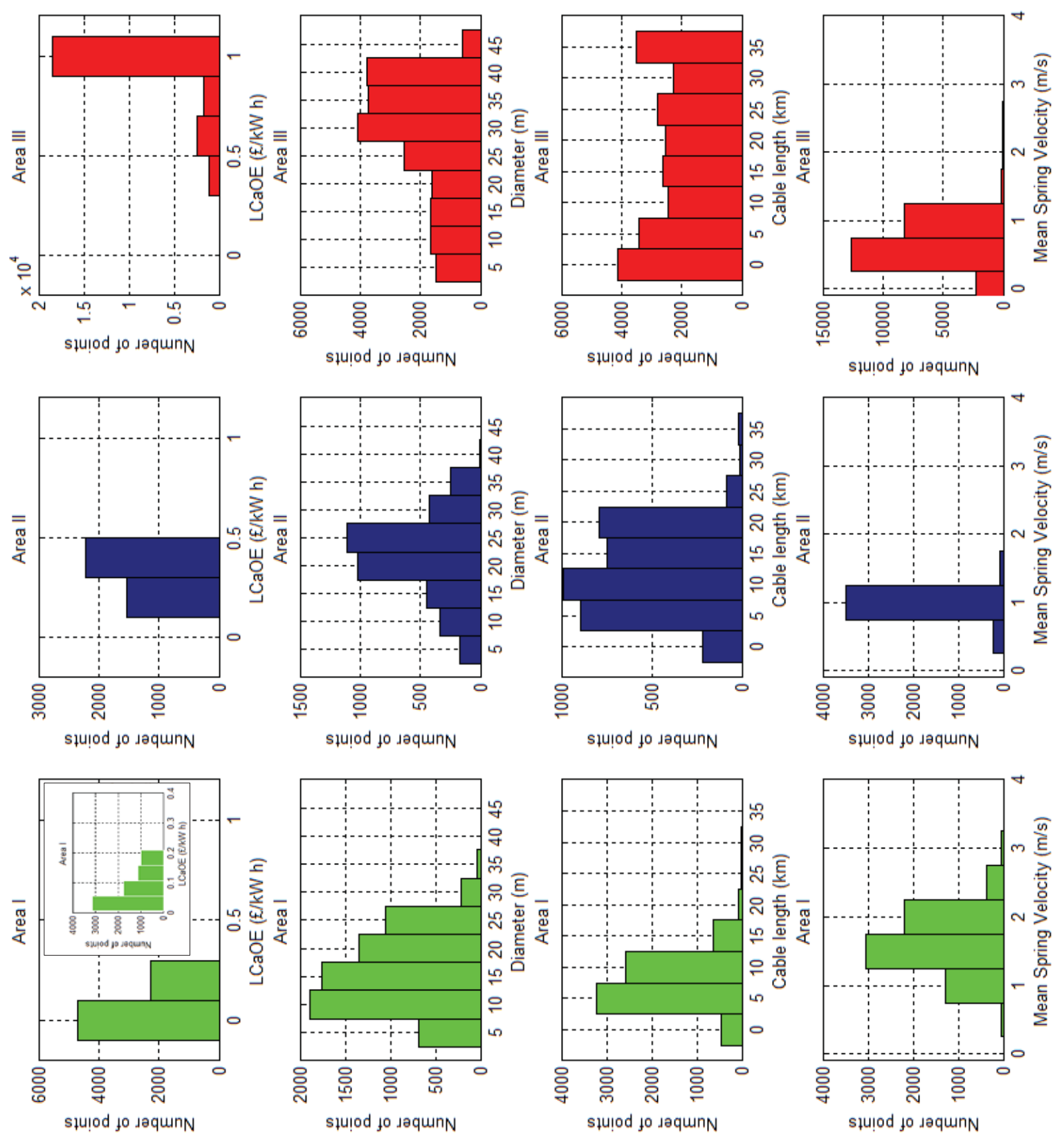


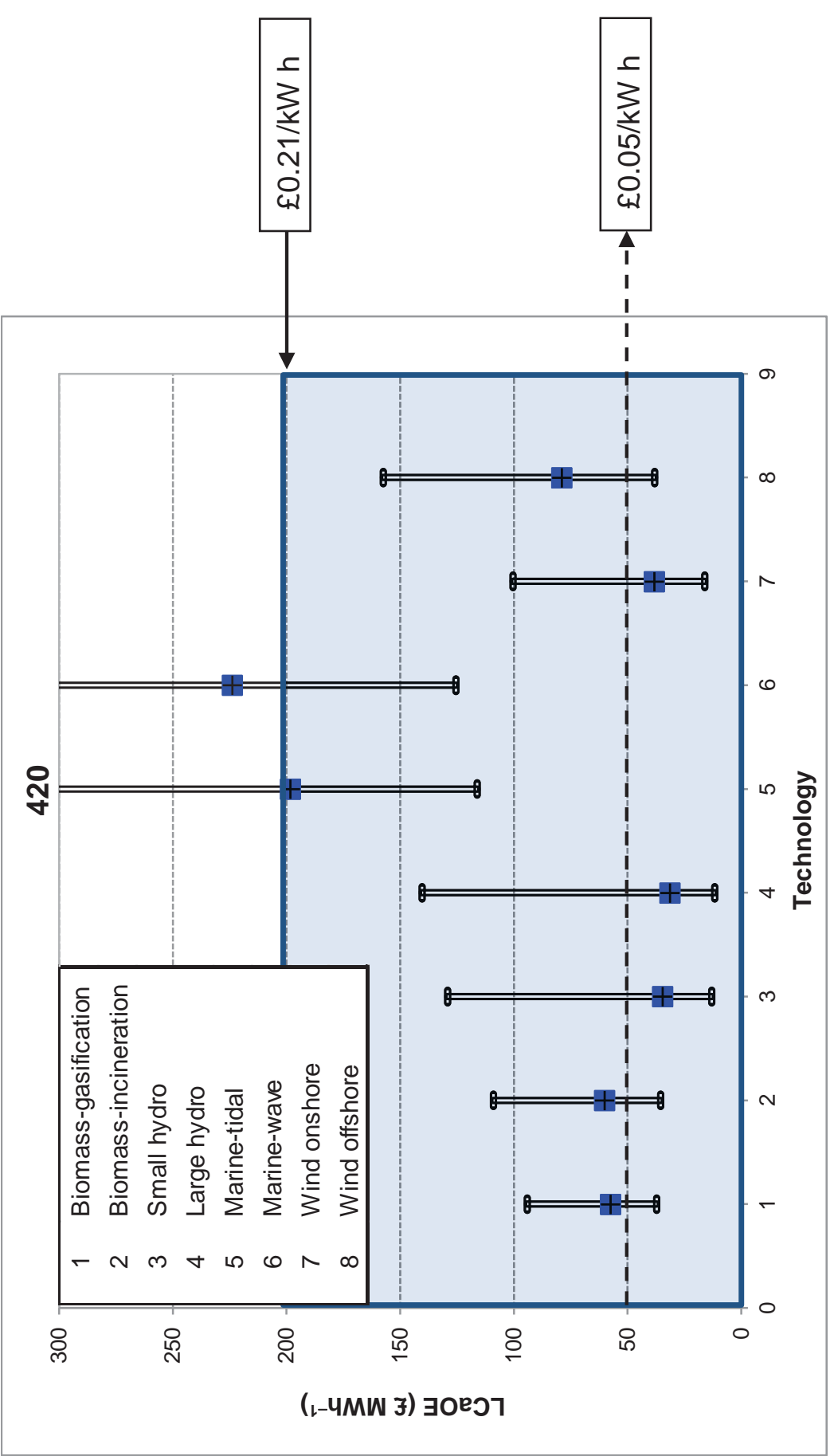



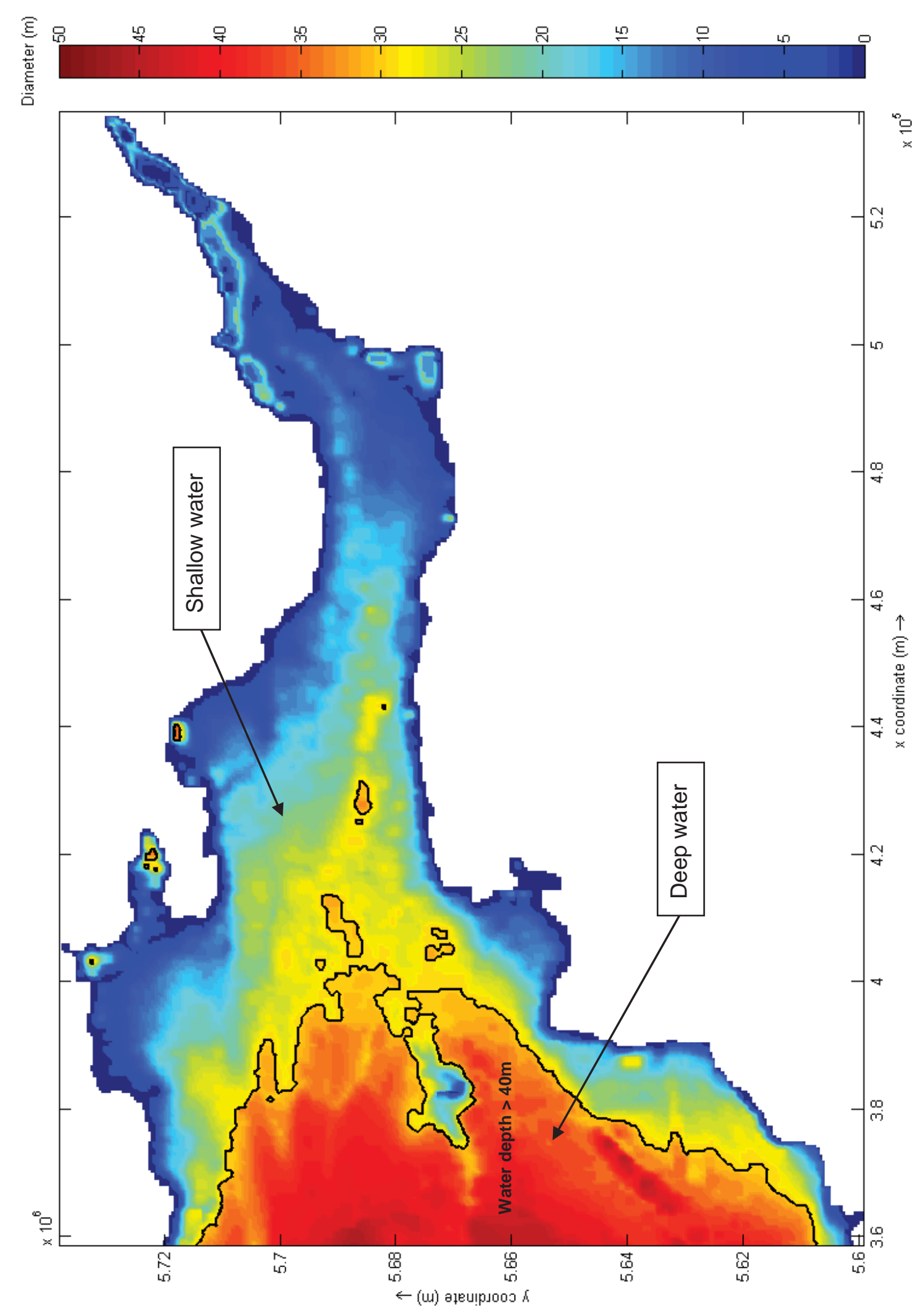


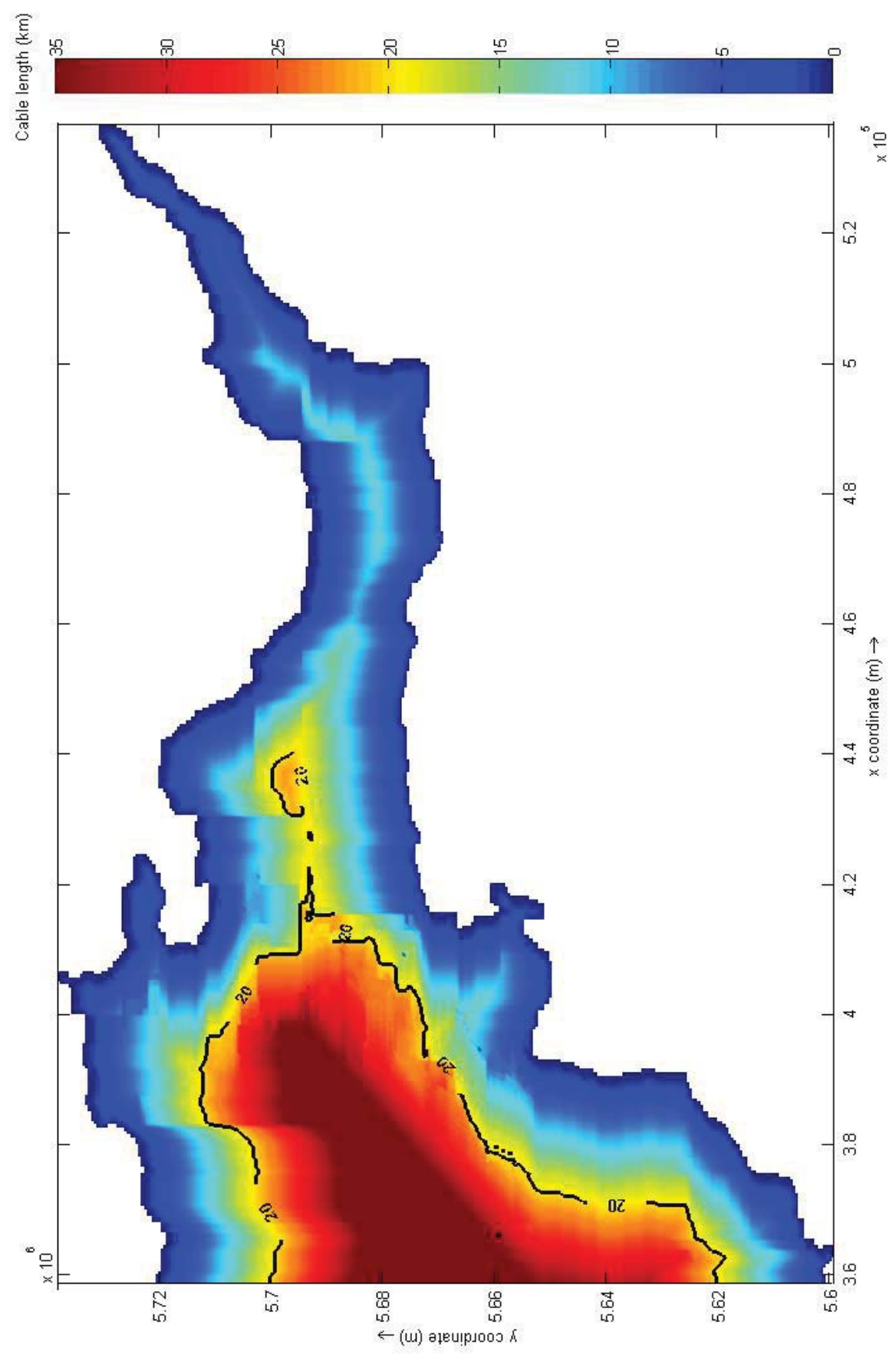

$\hat{0}$
$\stackrel{0}{\frac{0}{5}}$
ioํㄴ 


$$
2
$$




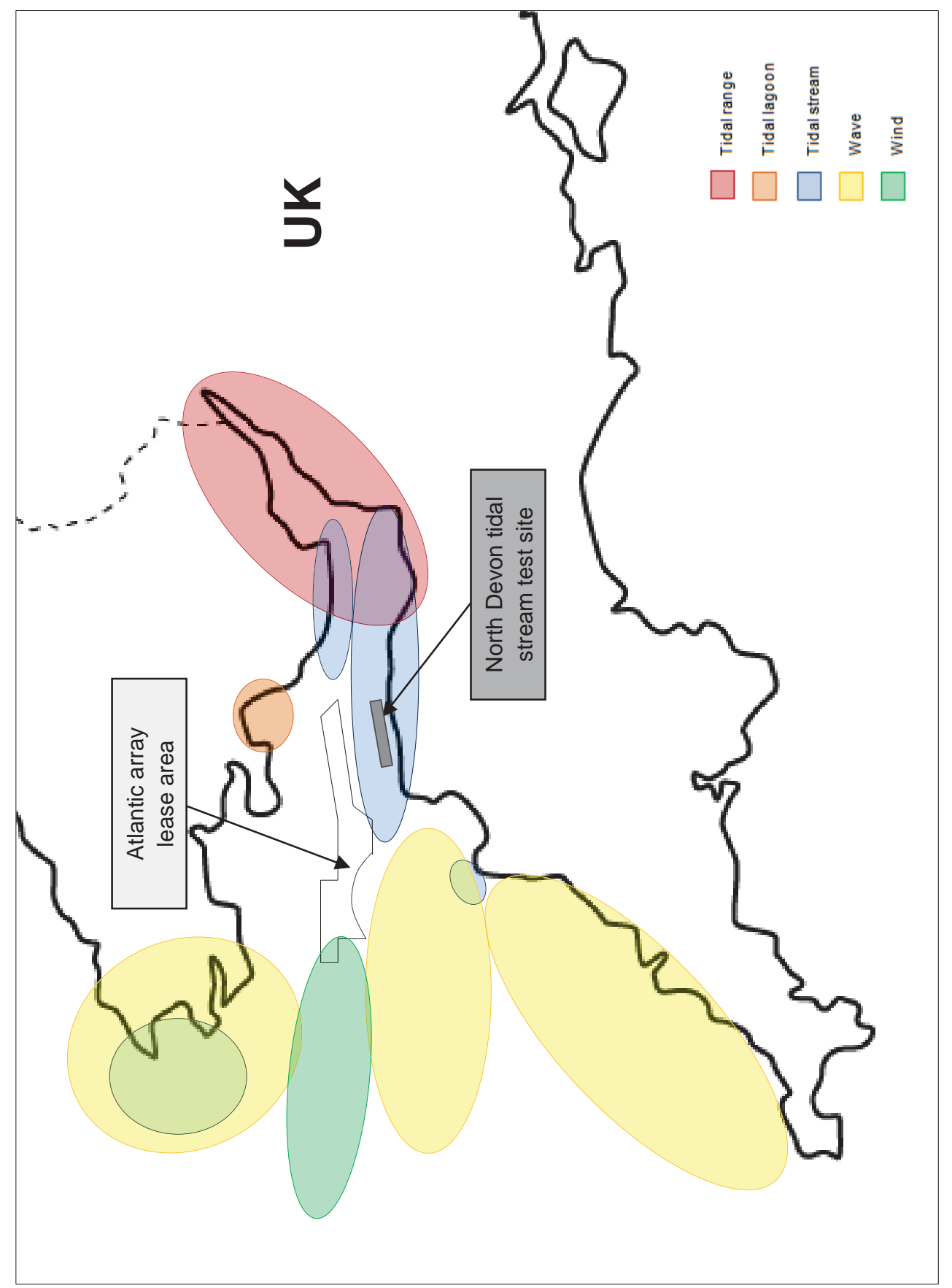

a
$\frac{0}{2}$
$\frac{0}{2}$
in 


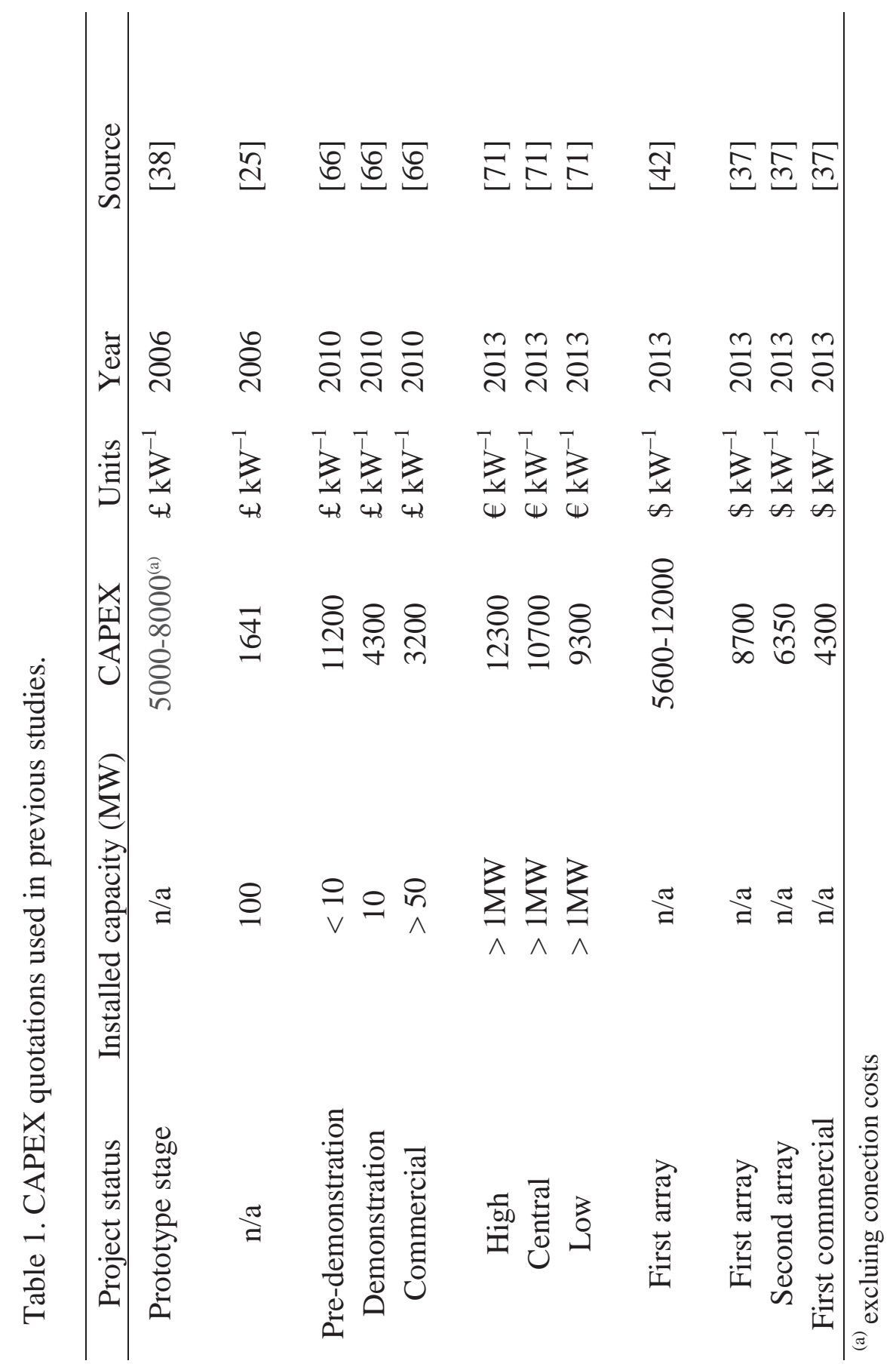


Table 2

Table 2. LCaOE input parameters

\begin{tabular}{cr}
\hline Parameter & Value \\
\hline$\lambda_{(\mathrm{R}+\mathrm{C}+\mathrm{F})}$ & $70 \%$ \\
$C_{p}$ & 0.4 \\
$r$ & $10 \%$ \\
$T$ & 20 years \\
\hline
\end{tabular}


Table 3

Table 3. LCaOE ranges across the study domain

\begin{tabular}{cc}
\hline Area & LCaOE $(£$ per $\mathrm{kWh})$ \\
\hline I & $<0.21$ \\
II & $0.21-0.42$ \\
III & $>0.42$ \\
\hline
\end{tabular}


Table 4. LCaOE estimates: traditional vs. new approach.

\begin{tabular}{rcc}
\hline & Point $a$ & Point $b$ \\
\hline \multicolumn{1}{c}{ Coordinates } & & \\
$\left(\mathrm{x} 10^{5}, \mathrm{y} 10^{6}\right)$ & $(3.7093,5.6597)$ & $(4.3443,5.6777)$ \\
$D(\mathrm{~m})$ & 41 & 15 \\
$L(\mathrm{~km})$ & 28 & 3 \\
LCaOE (£ per kWh) traditional & & \\
approach & 0.1431 & 0.1414 \\
LCaOE (£ per kWh) new approach & $>1$ & 0.1419 \\
\hline
\end{tabular}

